\title{
Childhood maltreatment and the structure of common psychiatric disorders ${ }^{\dagger}$
}

Katherine M. Keyes, Nicholas R. Eaton, Robert F. Krueger, Katie A. McLaughlin, Melanie M. Wall, Bridget F. Grant and Deborah S. Hasin

\section{Background}

Previous research suggests that various types of childhood maltreatment frequently co-occur and confer risk for multiple psychiatric diagnoses. This non-specific pattern of risk may mean that childhood maltreatment increases vulnerability to numerous specific psychiatric disorders through diverse, specific mechanisms or that childhood maltreatment engenders a generalised liability to dimensions of psychopathology. Although these competing explanations have different implications for intervention, they have never been evaluated empirically.

\section{Aims}

We used a latent variable approach to estimate the associations of childhood maltreatment with underlying dimensions of internalising and externalising psychopathology and with specific disorders after accounting for the latent dimensions. We also examined gender differences in these associations.

\section{Method}

Data were drawn from a nationally representative survey of 34653 US adults. Lifetime DSM-IV psychiatric disorders were assessed using the AUDADIS-IV. Physical, sexual and emotional abuse and neglect were assessed using validated measures. Analyses controlled for other childhood adversities and sociodemographics.

\section{Results}

The effects were fully mediated through the latent liability dimensions, with an impact on underlying liability levels to internalising and externalising psychopathology rather than specific psychiatric disorders. Important gender differences emerged with physical abuse associated only with externalising liability in men, and only with internalising liability in women. Neglect was not significantly associated with latent liability levels.

\section{Conclusions}

The association between childhood maltreatment and common psychiatric disorders operates through latent liabilities to experience internalising and externalising psychopathology, indicating that the prevention of maltreatment may have a wide range of benefits in reducing the prevalence of many common mental disorders. Different forms of abuse have gender-specific consequences for the expression of internalising and externalising psychopathology, suggesting gender-specific aetiological pathways between maltreatment and psychopathology.

\section{Declaration of interest}

None.
Exposure to childhood maltreatment (i.e. abuse and/or neglect) has been shown to increase risk for many psychiatric disorders, including mood disorders, ${ }^{1-3}$ anxiety disorders, ${ }^{2,4}$ alcohol use disorders, ${ }^{1,4,5}$ drug use disorders, ${ }^{4,6}$ disruptive behaviour disorders, ${ }^{7,8}$ antisocial behaviour ${ }^{9}$ and psychosis. $^{10,11}$ Recent epidemiological research suggested that the onset of psychiatric disorders across the life course in nearly a third of cases is attributable to adverse childhood experiences, underscoring the public health significance of these exposures. ${ }^{7,12,13}$ The strong associations of childhood maltreatment with a wide range of psychiatric outcomes suggest that maltreatment may confer non-specific risk for psychopathology rather than risk for specific disorders. However, prior research has largely examined the associations of childhood maltreatment with individual psychiatric disorders, ${ }^{14-17}$ or broad classes of disorders (such as mood disorders) without accounting for comorbidity or the underlying structure of psychopathology. ${ }^{7,18}$ Therefore, it remains unknown whether childhood maltreatment increases risk for specific psychiatric disorders over and above a latent vulnerability to experience psychopathology.

Much research on childhood maltreatment has focused on a single type of maltreatment (such as sexual abuse or parental neglect) despite ample evidence demonstrating that these exposures frequently co-occur. ${ }^{19,20}$ Indeed, factor analysis in a clinical population showed that sexual abuse, physical abuse, emotional abuse and emotional neglect are distinct yet correlated

'See editorial, pp. 89-91, this issue. constructs representing different facets of childhood maltreatment. ${ }^{21}$ The underlying dimensions of childhood maltreatment have never been examined in a general population sample.

Previous studies examining the latent structure of common mental disorders in epidemiological samples have converged on two major dimensions that represent observed patterns of comorbidity among, and liability to experience, many common mental disorders. ${ }^{22,23}$ The internalising dimension indicates liability to experience mood and anxiety disorders such as major depression, generalised anxiety disorder, panic disorder and social phobia. The externalising dimension indicates liability to experience substance disorders, conduct disorder, and antisocial personality disorder. ${ }^{23,24}$ Adopting a latent liability dimensional approach to the study of common mental disorders has increased understanding of risk factors for psychopathology in numerous ways. ${ }^{23-25}$ For example, recent data from the World Health Organization World Mental Health (WHO-WMH) surveys found that almost all pair-wise comorbidity estimates between the onset of any two disorders were accounted for by the latent internalising and externalising dimensions, suggesting that most psychiatric comorbidity is explained by common underlying liabilities. ${ }^{13}$

Existing maltreatment research, however, has largely focused on identifying the impacts on specific disorders rather than these liabilities to experience internalising and externalising psychopathology. ${ }^{26,27}$ To our knowledge, the associations of childhood maltreatment with latent internalising and externalising dimensions of psychopathology and with specific disorders above and beyond these dimensions have never been examined. 
The present study addressed this gap in the literature. First, we examined whether five types of childhood maltreatment (emotional neglect, physical neglect, emotional abuse, physical abuse and sexual abuse) were associated with latent dimensions of internalising and externalising psychopathology, controlling for other childhood adversities and demographic characteristics. Second, we evaluated differences in the strength of the associations between childhood maltreatment and internalising $v$. externalising dimensions. Because the prevalence of both childhood maltreatment and psychiatric disorders differ between men and women, and because the association between childhood maltreatment and psychiatric outcomes varies by gender, we conducted all analyses separately for men and women. We used data from the National Epidemiologic Survey on Alcohol and Related Conditions (NESARC), a general population sample of adults in the USA. Our use of a latent variable approach to examine these associations allowed us to simultaneously model comorbidity among psychiatric disorders, co-occurrence among diverse types of childhood maltreatment and associations between these two domains.

\section{Method}

\section{Study design and sample}

Data were drawn from the 2004-2005 NESARC, a study of noninstitutionalised adults in the USA residing in homes or group quarters. Data for NESARC were collected at two time points: initial data were collected in 2001-2002 with 43093 participants (response rate: $81 \%$ of those eligible). A second assessment was conducted in 2004-2005 with 34653 participants $(86.7 \%$ of original sample; ineligible respondents included deceased, $n=1403$; deported, too disabled to participate, $n=781$; or on active duty in the armed forces, $n=950$ ). The cumulative response rate over both waves was $70.2 \%$. Young, Black and Hispanic individuals were oversampled. Data were weighted to reflect the demographic characteristics in the US population based on the 2000 census. $^{28}$ The research protocol, including written informed consent procedures, received full ethical review and approval from the US Census Bureau and the US Office of Management and Budget. Further details of the study design and sampling methods can be found elsewhere. ${ }^{28,29}$ The present study included the 34653 participants in the second assessment, which included the measures of childhood maltreatment. Among those who participated in the second assessment, $48 \%$ were women; $25.4 \%$ were less than 35 years old, $31.2 \%$ were $35-49$, $24.1 \%$ were $50-64$ and $19.3 \%$ were 65 or older. White participants comprised $70.9 \%$ of the sample, African Americans 11.1\%, Hispanics 11.5\%, Asian or Pacific Islanders 4.3\% and American Indians and Alaska Natives 2.2\%.

\section{Measures}

Participants were interviewed face to face with the Alcohol Use Disorder and Associated Disabilities Interview Schedule, DSM-IV version (AUDADIS-IV), ${ }^{30}$ a fully structured instrument designed for experienced lay interviewers.

\section{Childhood maltreatment}

Table 1 shows the nineteen questions that measured five types of childhood maltreatment, adapted from two empirically validated scales: the Conflict Tactics Scale (CTS $)^{31,32}$ and the Childhood Trauma Questionnaire (CTQ). ${ }^{21,33}$ The time frame for these questions was the first 17 years of life. All response options ranged from never (1) to very often (5), with the exception of emotional neglect, which ranged from 'never' to 'always' and was reverse coded for the purposes of analysis. A test-retest study of these items indicated excellent intraclass test-retest reliability coefficients ranging from 0.79 for physical abuse to 0.88 for emotional abuse. ${ }^{29}$ Experiences of maltreatment range in severity, context, salience and effect on the individual; thus we conceptualised each maltreatment construct as representing continuous dimensions of maltreatment (for example from little to no physical abuse, to mild forms of physical abuse occurring seldom throughout childhood, to extreme and chronic physical abuse throughout childhood). A confirmatory factor analysis with items as polytomous indicators of latent dimensions indicated that a five-factor model with a latent dimension for each maltreatment type provided excellent fit to the data among both men (comparative fit index $(\mathrm{CFI})=0.981$, Tucker-Lewis index $(\mathrm{TLI})=0.977$, root mean squared error of approximation $(\mathrm{RMSEA})=0.024) \quad$ and women $\quad(\mathrm{CFI}=0.985, \quad \mathrm{TLI}=0.982$, RMSEA $=0.031)$.

\section{Psychiatric disorders}

We examined 12 common psychiatric disorders that have been empirically shown to correspond with the internalising and externalising liability dimensions: ${ }^{34}$ these included mood disorders (major depression and dysthymia), anxiety disorders (generalised anxiety disorder, post-traumatic stress disorder (PTSD), panic disorder with or without agoraphobia, social phobia, specific phobia), antisocial personality disorder and substance disorders (alcohol misuse or dependence, cannabis misuse or dependence, any other illicit drug misuse or dependence and tobacco dependence). ${ }^{35}$ We included antisocial personality disorder, given the extensive literature on the placement of this personality disorder within the externalising spectrum. ${ }^{23,24,34}$ Because childhood maltreatment is associated with the onset of psychiatric disorder throughout the life course, ${ }^{7,36,37}$ we analysed lifetime diagnoses. Dichotomous indicators of the presence or absence of disorder were used as indicator variables of latent internalising/externalising dimensions, following the standards in the literature. ${ }^{22,34,35,38}$ The test-retest reliability of mood and anxiety disorder diagnoses ranged from fair $(0.42$, specific phobia) to good (0.64, major depressive disorder)..$^{29,39,40}$ The AUDADIS-IV alcohol and drug dependence diagnoses and antisocial personality disorder demonstrated good to excellent test-retest reliability (kappa $(\kappa)=0.67-0.84)$ in clinical and general population samples ${ }^{39,41-43}$ and good to excellent convergent, discriminant and construct validity in samples within the USA ${ }^{44-46}$ and internationally, ${ }^{40,47-50}$ including clinical reappraisals. Previous work on these data has documented that disorders on the internalising dimension are more prevalent among women and disorders on the externalising dimension are more prevalent among men, but that the underlying structure of the internalising/externalising dimensions are invariant across gender. ${ }^{51}$

\section{Control variables}

All models controlled for age, ethnicity and personal income, as well as five indictors of non-maltreatment childhood adversities: witnessing intimate partner violence against female caregivers, living with an adult who was a problem drinker or drug user, having a parent/guardian who went to jail or prison, having a parent/guardian who was admitted to hospital for a mental illness and having a parent/guardian who attempted or died by suicide.

\section{Statistical analysis}

We estimated a structural equation model regressing latent psychiatric disorder factors on latent childhood maltreatment 


\begin{tabular}{|c|c|c|}
\hline Subscale and item & Men, $\%^{a}$ & Women, $\%^{\mathrm{a}}$ \\
\hline \multicolumn{3}{|l|}{ Physical neglect ${ }^{\mathrm{b}}$} \\
\hline How often were you made to do chores too difficult or dangerous for someone your age? & 3.26 & 4.12 \\
\hline How often were you left alone or unsupervised when you were too young to be alone? & 3.68 & 4.44 \\
\hline How often did you go without things you needed like clothing, shoes, or school supplies? & 2.1 & 2.96 \\
\hline How often did a parent or other adult living in your home make you go hungry or not prepare regular meals? & 0.88 & 1.4 \\
\hline How often did a parent or other adult living in your home ignore or fail to get you medical treatment when you were sick or hurt? & 0.76 & 1.36 \\
\hline \multicolumn{3}{|l|}{ Emotional abuse $^{c}$} \\
\hline How often did a parent or other adult living in your home swear at you, insult you or say hurtful things? & 4.47 & 6.48 \\
\hline How often did a parent or other adult living in your home threaten to hit you or throw something at you, but didn't do it? & 4.15 & 4.45 \\
\hline $\begin{array}{l}\text { How often did a parent or other adult living in your home act in any other way that made you afraid that you would be } \\
\text { physically hurt or injured? }\end{array}$ & 3.14 & 4.85 \\
\hline \multicolumn{3}{|l|}{ Physical abuse ${ }^{c}$} \\
\hline How often did a parent or other adult living in your home push, grab, shove, slap or hit you? & 3.73 & 5.04 \\
\hline How often did a parent or other adult living in your home hit you so hard that you had marks or bruises or were injured? & 1.92 & 2.94 \\
\hline \multicolumn{3}{|l|}{ Sexual abuse ${ }^{\mathrm{b}}$} \\
\hline \multicolumn{3}{|l|}{$\begin{array}{l}\text { How often an adult engaged in the following when the respondent either did not want them to or was too young to know what } \\
\text { was happening: }\end{array}$} \\
\hline Touch or fondle you in a sexual way when you didn't want them to or when you were too young to know what was happening? & 0.34 & 2.58 \\
\hline Have you touch their body in a sexual way when you didn't want to or you were too young to know what was happening? & 0.25 & 1.64 \\
\hline Attempt to have sexual intercourse with you when you didn't what them to or you were too young to know what was & & \\
\hline happening? & 0.19 & 1.47 \\
\hline Actually have sexual intercourse with you when you didn't want them to or you were too young to know what was happening? & 0.15 & 1.13 \\
\hline \multicolumn{3}{|l|}{ Emotional neglect $\mathrm{b}^{\mathrm{b}, \mathrm{d}}$} \\
\hline \multicolumn{3}{|l|}{ The extent to which respondents agreed with these statements about the family when growing up: } \\
\hline I felt there was someone in my family who wanted me to be a success & 6.77 & 9.19 \\
\hline There was someone in my family who helped me feel that I was important or special & 5.52 & 6.76 \\
\hline My family was a source of strength and support & 5.44 & 7.81 \\
\hline I felt that I was part of a close-knit family & 6.99 & 8.95 \\
\hline Someone in my family believed in me & 3.37 & 5.08 \\
\hline
\end{tabular}

factors. Given the response options (scores from one to five), maltreatment indicators were analysed as ordered categorical variables with a weighted least squares estimator (WLSMV). We evaluated a model in which internalising and externalising dimensions were regressed on all childhood maltreatment factors. In all models, internalising and externalising were allowed to correlate, and all of the childhood maltreatment factors were allowed to correlate with each other. Model fit indices examined included CFI, TLI and RMSEA. Hu \& Bentler recommended CFI and TLI values above 0.95 and RMSEA values below 0.06 , as representing a good model fit. ${ }^{52}$ We also evaluated modification indices to determine whether residual correlation between latent maltreatment factors and specific disorders would appreciably improve the model fit, with a deciding rule that direct effects between internalising and externalising dimensions and individual disorders would be included in the model if the expected model fit improvement was above 3.96, corresponding to a $P$ of 0.05 . Next, we evaluated variation in the size of regression coefficients by gender and across internalising and externalising by comparing nested models and testing differences between them with a robust chi-squared difference test (DIFFTEST in Mplus) suitable for use with WLSMV estimators. ${ }^{53}$ All analyses were conducted using Mplus version 6.0 for Windows. ${ }^{54}$ Estimates were sample weighted and standard errors were adjusted for the complex sample design of the NESARC survey (nested sampling by geographic strata and primary sampling unit). In all analyses, we conducted sensitivity analysis by removing all respondents with a diagnosis before age 18 to ensure temporal precedence of childhood maltreatment over psychiatric disorder; all results were unchanged, therefore the present paper includes the entire sample. We conducted further sensitivity analyses by randomly splitting the sample in half and re-estimating all models within each half by gender in order to establish the robustness of the results to random variation.

\section{Results}

\section{Prevalence of childhood maltreatment in the general population}

Table 1 provides details of the percentage of individuals reporting frequent exposure (often or very often) to each type of childhood maltreatment. Emotional neglect was the most commonly reported childhood maltreatment, with prevalence ranging from 3.4 to $9.2 \%$. Frequent unwanted sexual intercourse was the least common, with a prevalence of $0.2 \%$ in men and $1.1 \%$ in women. All experiences were significantly more common among women $(P<0.01)$, with the exception of a caregiver threatening 'to hit or throw something at you' $(P=0.24)$.

\section{Exploratory factor analysis of psychiatric disorders}

Because the prevalence of each psychiatric disorder has been shown to be significantly different between men and women in the NESARC, we conducted exploratory factor analysis of the psychiatric disorders within each gender. Exploratory factor analysis of the tetrachoric correlation matrix using Geomin rotated loadings (an oblique rotation that allows for correlated factors) indicated that a two-factor model provided the best representation of psychiatric disorders among both men 
$(\mathrm{CFI}=0.99, \mathrm{TLI}=0.98, \mathrm{RMSEA}=0.02$, standardised root mean square residual $(\mathrm{SRMR})=0.04)$ and women $(\mathrm{CFI}=0.99$, $\mathrm{TLI}=0.98, \quad \mathrm{RMSEA}=0.02, \quad \mathrm{SRMR}=0.03)$. Disorders on the internalising dimension included two mood disorders (major depressive disorder and dysthymia) and five anxiety disorders (generalised anxiety disorder, panic disorder with or without agoraphobia, social phobia, specific phobia and PTSD). The magnitude of loadings ranged from 0.52 (specific phobia on internalising in men) to 0.94 (marijuana misuse/dependence on externalising in women). No appreciable cross-loadings were detected, and internalising and externalising factors were correlated at $0.376(P<0.01)$.

\section{Associations between childhood maltreatment types and latent psychiatric disorder dimensions}

Using structural equation modelling we regressed the internalising and externalising dimensions on each of the five childhood maltreatment dimensions separately for men (Fig. 1) and women (Fig. 2). For simplicity, we show each latent dimension of childhood maltreatment without the indicator variables; indicator variables that correspond to each maltreatment factor are shown in Table 1. Residual variance in internalising and externalising dimensions was allowed to correlate in the model with both dimensions as simultaneous dependent variables, allowing the model to take into account residual association between internalising and externalising not accounted for by the predictor variables.

Among men, sexual abuse was associated with both internalising $(\beta=0.328$, s.e. $=0.09, \quad P<0.001)$ and externalising $(\beta=0.169$, s.e. $=0.09, P \leqslant 0.001$ ) dimensions (Fig. 1). Physical abuse was associated only with the externalising dimension $(\beta=0.240$, s.e. $=0.11, P=0.034)$ and emotional abuse was associated only with the internalising dimension $(\beta=0.344$, s.e. $=0.13$, $P=0.006$ ). The model explained $34 \%$ of the variance in the internalising factor and $31 \%$ of the variance in the externalising factor. Model fit indices all indicated that the model provided a good fit to the data $(\mathrm{CFI}=0.967, \mathrm{TLI}=0.964$, RMSEA $=0.015)$. Modification indices did not suggest any direct effects between latent maltreatment factors and individual disorders unmediated by the association with the disorder with the latent dimensions (no expected change in model fit was higher than 3.96, corresponding to a $P$ of 0.05 ).

Among women, sexual abuse and emotional abuse were associated with both internalising $(\beta=0.373, \quad$ s.e. $=0.10$, $P \leqslant 0.001)$ and externalising dimensions $(\beta=0.313$, s.e. $=0.08$, $P \leqslant 0.001$ ) (Fig. 2). Physical abuse was only associated with the internalising dimension $(\beta=0.496$, s.e. $=0.14, P<0.001)$. The model explained $33 \%$ of the variance in the internalising factor and $36 \%$ of the variance in the externalising factor. Modification indices did not suggest any direct effects between latent maltreatment factors and individual disorders unmediated by the association with the disorder with the latent dimensions.

\section{Variation in regression coefficients across internalising-externalising dimensions}

We tested whether the magnitude of the regression coefficients differed by internalising and externalising dimensions among men and women separately (Table 2). Among men, sexual abuse and emotional abuse were more strongly related to internalising liability $\left(\chi^{2}(1)=14.5, \quad P<0.001\right.$ and $\chi^{2}(1)=5.7, \quad P=0.02$, respectively), whereas physical abuse was more strongly related to externalising liability $\left(\chi^{2}(1)=6.9, P=0.009\right)$. Among women, physical abuse and emotional abuse were more strongly related to internalising liability $\left(\chi^{2}(1)=5.7, P=0.02\right.$ and $\chi^{2}(1)=5.1$, $P=0.02$ respectively) compared with externalising liability. Emotional neglect was more strongly related to internalising than externalising liability $\left(\chi^{2}(1)=4.9, \quad P=0.03\right)$, although the magnitudes of the association, and the differences, were weak.

\section{Sensitivity analysis}

The large sample size of the NESARC afforded the opportunity to conduct sensitivity analyses by randomly dividing the sample in half within each gender and re-estimating all models within the two halves to validate the results. We found that the two-factor model of internalising and externalising provided excellent fit among men in Sample $1 \quad(\mathrm{CFI}=0.982, \quad \mathrm{TLI}=0.973$, RMSEA $=0.021)$, women in Sample $1(\mathrm{CFI}=0.984, \mathrm{TLI}=0.976$, RMSEA $=0.019)$, men in Sample $2(\mathrm{CFI}=0.979$, TLI $=0.967$, RMSEA $=0.022)$, and women in Sample $2(\mathrm{CFI}=0.989$, $\mathrm{TLI}=0.983$, RMSEA $=0.017$ ). We also found that a five-factor model of childhood maltreatment provided excellent fit among men in Sample $1(\mathrm{CFI}=0.983, \mathrm{TLI}=0.979, \mathrm{RMSEA}=0.017)$, women in Sample $1(\mathrm{CFI}=0.985$, TLI $=0.981, \mathrm{RMSEA}=0.024)$, men in Sample $2(\mathrm{CFI}=0.983$, TLI $=0.979, \quad \mathrm{RMSEA}=0.017)$, and women in Sample $2 \quad(\mathrm{CFI}=0.987, \quad \mathrm{TLI}=0.984$, RMSEA $=0.023$.

Online Table DS1 provides beta estimates, $P$-values and chisquared difference testing across the two samples among both men and women. The results were generally consistent with those in the full sample, with the exception of minor variations in statistical significance likely due to reduced power to detect effects.

\begin{tabular}{|c|c|c|c|c|c|}
\hline & \multirow[b]{2}{*}{$n$} & \multirow{2}{*}{$\begin{array}{l}\text { Association with internalising } \\
\text { dimension, } \beta\end{array}$} & \multirow{2}{*}{$\begin{array}{l}\text { Association with externalising } \\
\text { dimension, } \beta\end{array}$} & \multicolumn{2}{|c|}{ Test of difference } \\
\hline & & & & $\chi^{2}$ (d.f) & $P$ \\
\hline Men & 14564 & & & & \\
\hline Emotional neglect & & 0.018 & 0.013 & $1.45(1)$ & 0.24 \\
\hline Physical neglect & & -0.033 & -0.046 & $1.11(1)$ & 0.22 \\
\hline Emotional abuse & & 0.344 & 0.023 & $5.72(1)$ & 0.02 \\
\hline Physical abuse & & -0.098 & 0.240 & $6.92(1)$ & 0.009 \\
\hline Sexual abuse & & 0.328 & 0.169 & 14.49 (1) & $<0.001$ \\
\hline Women & 20089 & & & & \\
\hline Emotional neglect & & 0.008 & -0.036 & $4.93(1)$ & 0.03 \\
\hline Physical neglect & & -0.064 & -0.029 & $0.08(1)$ & 0.78 \\
\hline Emotional abuse & & 0.852 & 0.355 & $5.13(1)$ & 0.02 \\
\hline Physical abuse & & 0.496 & -0.061 & $5.72(1)$ & 0.02 \\
\hline Sexual abuse & & 0.373 & 0.313 & $3.66(1)$ & 0.06 \\
\hline
\end{tabular}




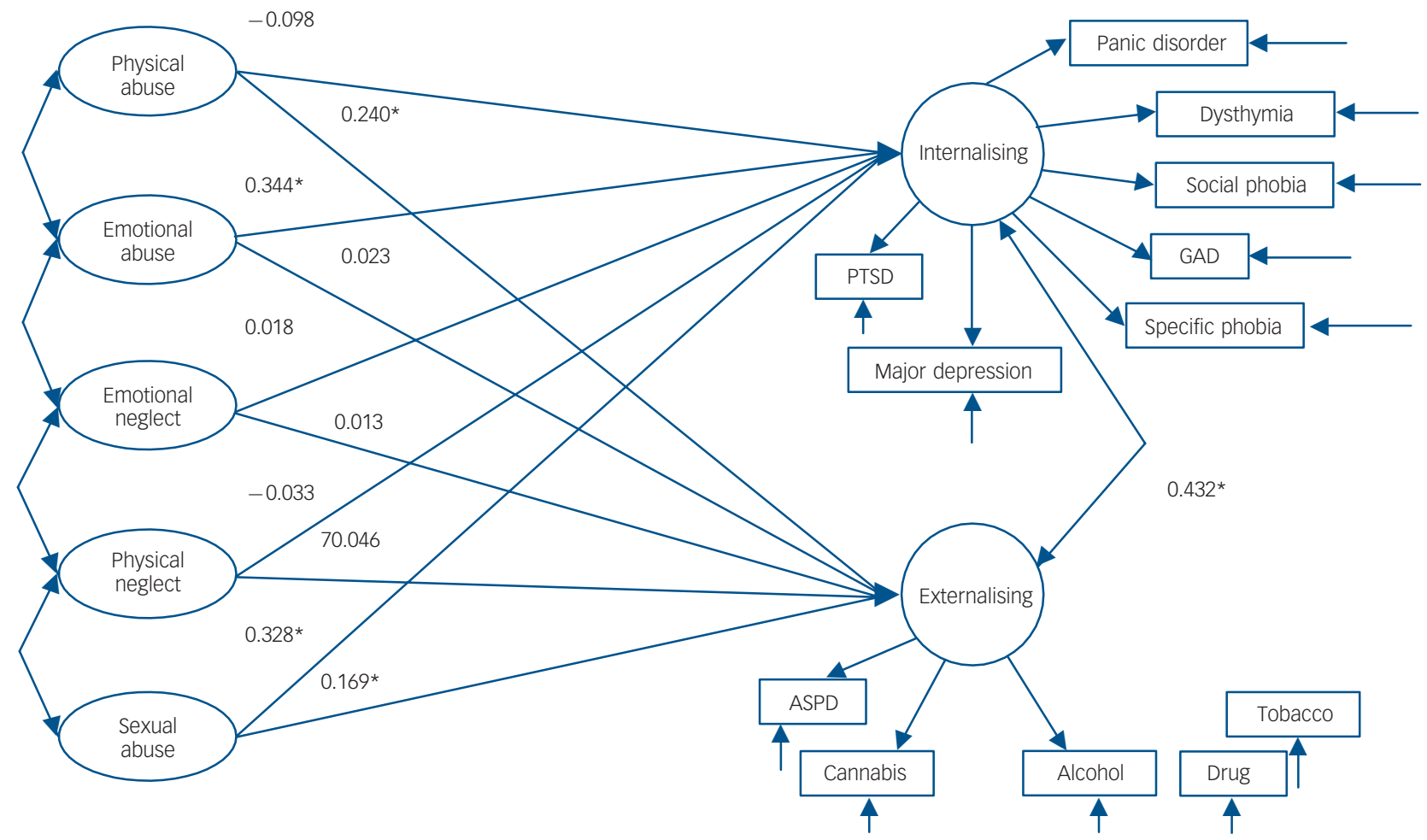

Fig. 1 Structural equation model indicating the association between latent dimensions of adverse childhood events and latent dimensions of internalising and externalising psychopathology liability in a general population sample of men in the USA $(n=14564)$.

Childhood adversity factors were allowed to correlate with each other $(P<0.01$ for all correlations). Psychiatric disorder factors were allowed to correlate with each other $(P<0.01$ for all correlations). Panic disorder, panic disorder with or without agoraphobia; GAD, generalised anxiety disorder; PTSD, post-traumatic stress disorder; ASPD, antisocial personality disorder; Cannabis, cannabis misuse/dependence; Alcohol, alcohol misuse/dependence; Drug, drug misuse/dependence on illicit drugs other than cannabis; Tobacco, nicotine dependence * Statistically significant regression coefficient at the $P<0.05$ level.

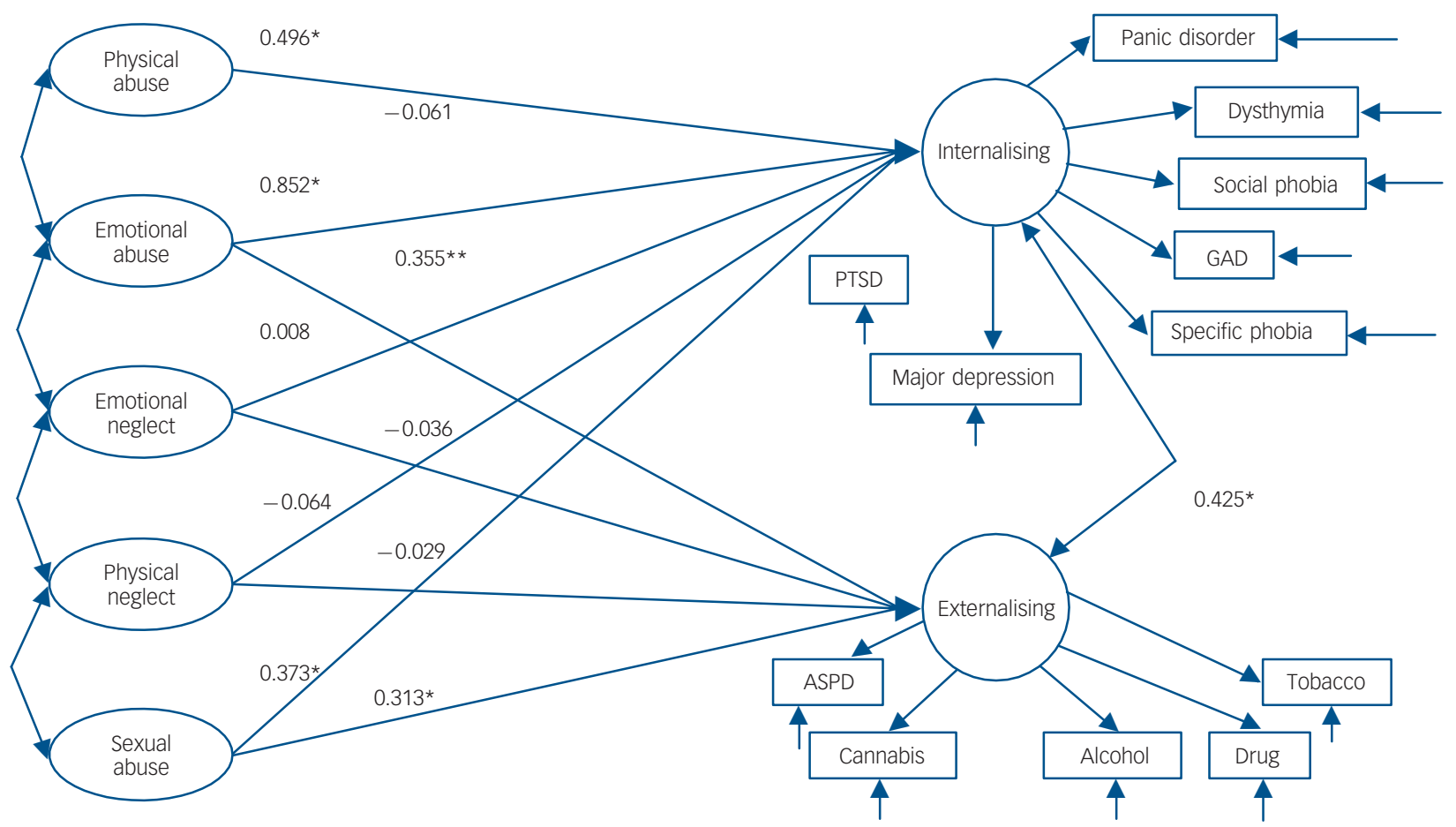

Fig. 2 Structural equation model indicating the association between latent dimensions of adverse childhood events and latent dimensions of internalising and externalising psychopathology liability in a general population sample of women in the USA $(n=20089)$.

Childhood adversity factors were allowed to correlate with each other $(P<0.01$ for all correlations). Psychiatric disorder factors were allowed to correlate with each other $(P<0.01$ for all correlations). Panic disorder, panic disorder with or without agoraphobia; GAD, generalised anxiety disorder; PTSD, post-traumatic stress disorder; ASPD, antisocial personality disorder; Cannabis, cannabis misuse/dependence; Alcohol, alcohol misuse/dependence; Drug, drug misuse/dependence on illicit drugs other than cannabis; Tobacco, nicotine dependence. * ${ }^{\star}$ tatistically significant regression coefficient at the $P<0.05, * * P=0.05$ level. 
Specifically, among men, emotional abuse was not significantly associated with internalising in Sample $1(\beta=0.250, P=0.12)$, but was significantly associated in Sample $2(\beta=0.504, P=0.02)$ and in the overall sample (Fig. $1, \beta=0.344, P=0.03)$ ). Among women, emotional abuse was marginally significantly associated with the externalising dimension in the overall sample ( $\beta=0.355, P=0.05)$, and was not significantly associated in the split samples (Sample 1: $B=0.219, P=0.40$; Sample 2=0.118, $P=0.59$ ). Comparisons of the strength of the effects between internalising and externalising dimensions produced results consistent with those in the full sample presented in Table 2.

\section{Discussion}

\section{Main findings}

Four novel findings emerged in the present study. First, we showed that the association between childhood maltreatment and psychiatric disorders were fully mediated through the associations of maltreatment with estimated latent internalising and externalising dimensions rather than through specific disorders. That is, once associations between the childhood maltreatment and the internalising and externalising dimensions were estimated, some maltreatment events were no longer significantly associated with psychopathology, and among those that remained significant, there were no residual associations between maltreatment and any specific measured disorder. This means that any observed association between childhood maltreatment and the psychiatric disorders measured here actually reflect the association of maltreatment with an underlying liability to experience internalising and externalising psychopathology.

Second, once all types of maltreatment and other childhood adversities were controlled for, our data indicated that all forms of abuse (physical, emotional and sexual) were associated with at least one dimension of psychopathology, whereas emotional and physical neglect were not associated with either the internalising or externalising dimensions. However, the results of our split-sample sensitivity analysis indicated that emotional abuse estimates should be interpreted with caution; although the direction and magnitude of emotional abuse estimates were consistent in the split samples and in the full sample, statistical significance varied, indicating that the robustness of these findings is questionable.

Third, specific types of maltreatment had specific patterns of association with the internalising or externalising dimensions. For example, sexual abuse was associated more strongly with the internalising dimension than the externalising dimension in both men and women.

Finally, the patterns of association between maltreatment and the underlying psychopathology dimensions differed by gender. Physical abuse was associated with only externalising liability in men, but was associated with only internalising liability in women.

Overall, these results underscore the pernicious mental health consequences of childhood maltreatment for mental health across the life course and suggest that the prevention of maltreatment, particularly childhood abuse, may have broad benefits for many common mental disorders.

\section{Comparison with previous studies}

Our results are consistent with previous work documenting both the high co-occurrence of different types of childhood maltreatment and the robust associations of these exposures with multiple types of psychiatric disorders. ${ }^{37,55-57}$ We extend this literature by using a latent variable approach, which accounts for the co-occurrence of both childhood maltreatment and psychiatric disorders simultaneously. This approach allowed us both to examine the associations among maltreatment dimensions and broad vulnerabilities to internalising and externalising psychopathology and to identify maltreatment experiences that were differentially associated with these psychopathology dimensions. This advances previous research that evaluated the relationship of childhood maltreatment with specific disorders ${ }^{1,58-61}$ by showing specificity in the associations of maltreatment types with internalising and externalising psychopathology. Here, we found that neither physical nor emotional neglect predicted psychopathology once other maltreatment types were considered. Sexual abuse was more strongly associated with internalising than with externalising disorders, a finding that stands in contrast with those reported from an epidemiological co-twin sample of women, where sexual abuse was associated most strongly with alcohol and drug disorders. ${ }^{1}$ Our approach involved a more rigorous analytic strategy with comprehensive controls for other childhood adversities and comorbid psychopathology; however, further research on the strength of the associations of maltreatment with internalising and externalising liabilities is warranted.

A pervasive limitation in prior research on childhood maltreatment and mental health has been a focus on a single diagnostic outcome, ${ }^{14-17}$ which inflates the strength of relationships with specific disorders due to comorbidity and assumes that categorical psychiatric diagnoses correctly parse psychopathology into discrete absent versus present manifestations. Our latent variable approach allowed us to test for specificity in the associations among childhood maltreatment and psychiatric disorders unmediated by the latent internalising and externalising dimensions. We found no associations between maltreatment and specific measured psychiatric disorders that were unmediated by the latent internalising-externalising dimensions. This research extends recent work from the WHO-WMH surveys demonstrating that that lifetime comorbidity between disorders is also accounted for by latent internalising and externalising dimensions, ${ }^{13}$ indicating the importance of latent dimensions for improving our understanding of risk factors for common psychiatric disorders, in addition to their utility in understanding underlying patterns of comorbidity among disorders.

\section{Strengths and limitations}

Non-causal mechanisms could give rise to the effects found in the form of reverse causation and confounding. Recent research has demonstrated some evidence for reverse causation, whereby children and adolescents with conduct disorder are more likely to experience harsh parenting compared with children without such a disorder. ${ }^{62}$ We conducted a sensitivity analyses in order to refine the temporal assessment of childhood events and psychopathology; specifically, we removed individuals with an onset of a psychiatric disorder before age 18. Results were unchanged, reducing concerns about reverse causation. Ruling out common causes of exposure and outcome is more complex. For example, previous studies have demonstrated that both stressful life events and psychiatric disorders can be inherited, ${ }^{63}$ suggesting that a common genetic effect may account for some of the observed association. Further, childhood maltreatment is more likely to occur in households characterised by instability, ${ }^{19,64}$ poverty ${ }^{65}$ and parental dysfunction across multiple domains including substance misuse, criminality and psychopathology. ${ }^{66-70}$ However, our models included rigorous controls for other childhood 
adversities, including exposure to alcohol, drugs and violence in the home, as well as living with a parent/guardian who was afflicted with mental illness severe enough to be admitted to hospital, or who attempted or died by suicide. Although these covariates do not capture all possible adverse childhood exposures, our results indicated robust associations with childhood maltreatment over and above the effects of other adverse childhood experiences. Future directions of this work include assessment of whether the latent associations between maltreatment and psychopathology account for gender differences in observed prevalence rates. Previous work has demonstrated that the internalising-externalising structure is gender invariant and that differences in the mean levels of internalising and externalising are what account for gender differences in prevalence rates. ${ }^{51}$ Thus, it is reasonable to think that these maltreatments contribute to the mean-level differences in internalising and externalising, which filters down to specific disorder prevalence rates.

The most potentially problematic limitation of these data is the retrospective reporting of childhood maltreatment. ${ }^{57,71}$ Longitudinal studies have documented that child abuse reports, including childhood sexual abuse, are unstable over time. ${ }^{72-75}$ Studies testing the validity of retrospective self-report generally find few false positives, indicating that the consequence of unstable reporting is that the prevalence of childhood maltreatment assessed at only one time point is likely underestimated. ${ }^{73-75}$ Further, prospective data have indicated that relative risks for the association between childhood maltreatment and psychiatric disorders remained stable across different approaches to classifying individuals, and that mood at the time of the interview was unassociated with instability. ${ }^{75,76}$ These findings reduce concerns about systematic biases in retrospective reports. The estimates of childhood maltreatment in these data are lower than those reported in other large-scale epidemiological surveys; ${ }^{7,12,77}$ although we estimated prevalence of frequent rather any maltreatment. Thus, a higher threshold for reporting may account for these differences, and results across studies should be compared with caution. Further, these data lack information about psychotic disorders, ${ }^{10,11,78}$ which have also shown associations with childhood maltreatment. Whereas the present study focused on psychiatric disorders, other important psychological outcomes have been shown to be associated with childhood maltreatment including social introversion, guilt, selfesteem and coping style. ${ }^{79}$ Future research should incorporate psychological as well as psychiatric outcomes to comprehensively understand emotional and behavioural responses to trauma.

Despite these limitations, the NESARC is the largest psychiatric epidemiological survey of the US general population conducted to date, with strong measures of both childhood maltreatment and a wide range of psychiatric disorders. Our results provide a unique insight into the structures of childhood maltreatment and of common mental disorders as well as the robust relationship between them.

\section{Implications}

The underlying patterns evidenced in this study suggest that childhood abuse contributes risk for common psychiatric disorders by increasing vulnerabilities to express internalising and externalising psychopathology. Taken together, these results indicate that intervention to prevent childhood maltreatment may reduce broad liabilities to psychopathology rather than to individual disorders, leading to a consequential reduction in the prevalence of a wide range of psychiatric disorders. Further, these results underscore calls for mental health clinicians to incorporate assessments of childhood maltreatment into assessments of mental health service users, ${ }^{80}$ in order to provide adequate, evidence-based treatment to individuals who report such experiences.

\section{Katherine M. Keyes, PhD, MPH, Department of Epidemiology, Mailman School of Public Health and Department of Psychiatry, College of Physicians and Surgeons, Columbia University, New York; Nicholas R. Eaton, MA, Robert F. Krueger, PhD, Department of Psychology, University of Minnesota, Minneapolis; Katie A. McLaughlin, PhD, Division of General Pediatrics, Children's Hospital Boston, Harvard Medical School, Boston, Massachusetts; Melanie M. Wall, PhD, Department of Biostatistics, Mailman School of Public Health, Columbia University, New York Bridget F. Grant, PhD, PhD, Laboratory of Epidemiology and Biometry, Division of Intramural Clinical and Biological Research, National Institute on Alcohol Abuse and Alcoholism, National Institutes of Health, Department of Health and Human Services, Bethesda, Maryland; Deborah S. Hasin, PhD, Department of Epidemiology, Mailman School of Public Health and Department of Psychiatry, College of Physicians and} Surgeons, Columbia University, New York, USA

Correspondence: Katherine M. Keyes, Department of Epidemiology, Mailman School of Public Health, Columbia University, 1051 Riverside Drive 123, New York, NY 10032, USA. Email: kmk2104@columbia.edu

First received 13 Feb 2011, final revision 29 Jul 2011, accepted 15 Sep 2011

\section{Funding}

This research was supported in part by grants from the National Institute on Alcoholism and Alcohol Abuse (K05 AA014223 to D.S.H; U01 AA018111 to D.S.H), a fellowship from the National Institute of Drug Abuse (F31-DA026689 to K.M.K), the Robert Wood Johnson Foundation (Grant Number 053572 to K.A.M.), the National Institute of Mental Health (K01 MH092526 to K.A.M.) and support from New York State Psychiatric Institute.

\section{References}

1 Kendler KS, Bulik CM, Silberg J, Hettema JM, Myers J, Prescott CA. Childhood sexual abuse and adult psychiatric and substance use disorders in women: an epidemiological and cotwin control analysis. Arch Gen Psychiatry 2000; 57: 953-9.

2 Phillips NK, Hammen CL, Brennan PA, Najman JM, Bor W. Early adversity and the prospective prediction of depressive and anxiety disorders in adolescents. J Abnorm Child Psychol 2005; 33: 13-24.

3 Widom CS, DuMont K, Czaja SJ. A prospective investigation of major depressive disorder and comorbidity in abused and neglected children grown up. Arch Gen Psychiatry 2007; 64: 49-56.

4 Fergusson DM, Boden JM, Horwood $\sqcup$. Exposure to childhood sexual and physical abuse and adjustment in early adulthood. Child Abuse Negl 2008; 32: $607-19$

5 Clark DB, Lesnick L, Hegedus AM. Traumas and other adverse life events in adolescents with alcohol abuse and dependence. J Am Acad Child Adolesc Psychiatry 1997; 36: 1744-51.

6 Widom CS, Marmorstein NR, White HR. Childhood victimization and illicit drug use in middle adulthood. Psychol Addict Behav 2006; 20: 394-403.

7 Green JG, McLaughlin KA, Berglund P, Gruber MJ, Sampson NA, Zaslavsky $A M$, et al. Childhood adversities and adult psychopathology in the Nationa Comorbidity Survey Replication (NCS-R) I: associations with first onset of DSM-IV disorders. Arch Gen Psychiatry 2010; 62: 113-23.

8 Widom CS. Childhood victimization and adolescent problem behaviors. In Adolescent Problem Behaviors: Issues and Research (eds RD Ketterlinus \& ME Lamb): 127-64. Lawrence Erlbaum Association, 1994.

9 Johnson JG, Cohen P, Brown J, Smailes EM, Bernstein DP. Childhood maltreatment increases risk for personality disorders during early adulthood. Arch Gen Psychiatry 1999; 56: 600-6.

10 Arseneault L, Cannon M, Fisher HL, Polanczyk G, Moffitt TE, Caspi A. Childhood trauma and children's emerging psychotic symptoms: a genetically sensitive longitudinal cohort study. Am J Psychiatry 2011; 168: $65-72$.

11 Read J, van Os J, Morrison AP, Ross CA. Childhood trauma, psychosis and schizophrenia: a literature review with theoretical and clinical implications Acta Psychiatr Scand 2005; 112: 330-50.

12 Kessler RC, McLaughlin KA, Greif Green J, Gruber MJ, Sampson NA, Zaslavsky AM, et al. Childhood adversities and adult psychopathology in the WHO World Mental Health Surveys. Br J Psychiatry 2010; 197: 378-85. 
13 Kessler RC, Ormel J, Petukhova M, McLaughlin KA, Green JG, Russo L, et al. Development of lifetime comorbidity in the world health organization world mental health surveys. Arch Gen Psychiatry 2011; 68: 90-100.

14 Bifulco A, Brown GW, Adler Z. Early sexual abuse and clinical depression in adult life. Br J Psychiatry 1991; 159: 115-22.

15 Widom CS. Posttraumatic stress disorder in abused and neglected children grown up. Am J Psychiatry 1999; 156: 1223-9.

16 Sullivan PF, Bulik CM, Carter FA, Joyce PR. The significance of a history of childhood sexual abuse in bulimia nervosa. Br J Psychiatry 1995; 167: 679-82.

17 Chapman DP, Whitfield CL, Felitti VJ, Dube SR, Edwards VJ, Anda RF. Adverse childhood experiences and the risk of depressive disorders in adulthood. $J$ Affect Dis 2004; 82: 217-25.

18 Kendler KS, Bulik CM, Silberg JL, Hettema JM, Myers J, Prescott CA. Childhood sexual abuse and adult psychiatric and substance use disorders in women. Arch Gen Psychiatry 2000; 57: 953-9.

19 Dong $\mathrm{M}$, Anda RF, Felitti VJ, Dube SR, Williamson DF, Thompson TJ, et al. The interrelatedness of multiple forms of childhood abuse, neglect, and household dysfunction. Child Abuse Negl 2004; 28: 771-84.

20 Green JG, McLaughlin KA, Berglund PA, Gruber MJ, Sampson NA, Zaslavsky AM, et al. Childhood adversities and adult psychiatric disorders in the national comorbidity survey replication I: associations with first onse of DSM-IV disorders. Arch Gen Psychiatry 2010; 67: 113-23.

21 Bernstein DP, Fink L, Handelsman L, Foote J, Lovejoy M, Wenzel K, et al. Initial reliability and validity of a new retrospective measure of child abuse and neglect. Am J Psychiatry 1994; 151: 1132-6.

22 Krueger RF. The structure of common mental disorders. Arch Gen Psychiatry 1999; 56: 921-6.

23 Krueger RF, Hicks BM, Patrick CJ, Carlson SR, lacono WG, McGue M. Etiologic connections among substance dependence, antisocial behavior, and personality: modeling the externalizing spectrum. J Abnorm Psychol 2002; 111: 411-24.

24 Kendler KS, Prescott CA, Myers J, Neale MC. The structure of genetic and environmental risk factors for common psychiatric and substance use disorders in men and women. Arch Gen Psychiatry 2003; 60: 929-37.

25 Young SE, Stallings MC, Corley RP, Krauter KS, Hewitt JK. Genetic and environmental influences on behavioral disinhibition. Am J Med Genet 2000; 96: 684-95.

26 Kessler RC, Ormel J, Petukhova M, McLaughlin KA, Green JG, et al Development of lifetime comorbidity in the WHO World Mental Health (WMH) Surveys. Arch Gen Psychiatry 2011; 68: 90-100.

27 Krueger RF, Markon KE. A dimensional-spectrum model of psychopathology: progress and opportunities. Arch Gen Psychiatry 2011; 68: 10-1.

28 Grant BF, Goldstein RB, Chou SP, Huang B, Stinson FS, Dawson DA, et al. Sociodemographic and psychopathologic predictors of first incidence of DSM-IV substance use, mood and anxiety disorders: results from the Wave 2 National Epidemiologic Survey on Alcohol and Related Conditions. $\mathrm{Mol}$ Psychiatry 2009; 14: 1051-66.

29 Ruan WJ, Goldstein RB, Chou SP, Smith SM, Saha TD, Pickering RP, et al. The alcohol use disorder and associated disabilities interview schedule-IV (AUDADIS-IV): reliability of new psychiatric diagnostic modules and risk factors in a general population sample. Drug Alcohol Depend 2008; 92 27-36.

30 Grant BF, Dawson DA, Hasin DS. The Alcohol Use Disorder and Associated Disabilities Interview Schedule-DSM-IV Version. National Institute on Alcohol Abuse and Alcoholism, 2001.

31 Straus M. Measuring introfamily conflict and violence: the conflict tactice (CT) scales. J Marriage Fam 1979; 41: 75-88.

32 Straus M, Gelles RJ. Physical Violence in American Families: Risk Factors and Adaptations to Violence in 8,145 Families. Transaction Press, 1990.

33 Wyatt GE. The sexual abuse of Afro-American and White American women in childhood. Child Abuse Negl 1985; 9: 507-19.

34 Eaton NR, South SC, Krueger RF. The meaning of comorbidity among common mental disorders. In Contemporary Directions in Psychopathology (eds T Millon, RF Krueger \& E Simonsen): 223-41. Guilford Publications, 2010.

35 Hicks BM, Blonigen DM, Kramer MD, Krueger RF, Patrick CJ, lacono WG, et al. Gender differences and developmental change in externalizing disorders from late adolescence to early adulthood: a longitudinal twin study. J Abnorm Psychol 2007; 116: 433-47

36 McLaughlin KA, Green JG, Gruber M, Sampson NA, Zaslavsky A, Kessler RC Childhood adversities and adult psychopathology in the National Comorbidity Survey Replication (NCS-R): II. Associations with persistence of DSM-IV disorders. Arch Gen Psychiatry 2010; 62: 124-32.
37 Kessler RC, Davis CG, Kendler KS. Childhood adversity and adult psychiatric disorder in the US National Comorbidity Survey. Psychol Med 1997; 27: 1101-19.

38 Krueger RF, Caspi A, Moffitt TE, Silva PA. The structure and stability of common mental disorders (DSM-III-R): a longitudinal-epidemiological study. J Abnorm Psychol 1998; 107: 216-27.

39 Grant BF, Dawson DA, Stinson FS, Chou PS, Kay W, Pickering R. The Alcohol Use Disorder and Associated Disabilities Interview Schedule-IV (AUDADIS-IV): reliability of alcohol consumption, tobacco use, family history of depression and psychiatric diagnostic modules in a general population sample. Drug Alcohol Depend 2003; 71: 7-16.

40 Canino G, Bravo M, Ramirez R, Febo VE, Rubio-Stipec M, Fernández RL, et al The Spanish Alcohol Use Disorder and Associated Disabilities Interview Schedule (AUDADIS): reliability and concordance with clinical diagnoses in a Hispanic population. J Stud Alcohol 1999; 60: 790-9.

41 Grant BF, Harford TC, Dawson DA, Chou PS, Pickering RP. The Alcohol Use Disorder and Associated Disabilities Interview schedule (AUDADIS): reliability of alcohol and drug modules in a general population sample. Drug Alcohol Depend 1995; 39: 37-44.

42 Hasin D, Carpenter KM, Mccloud S, Smith M, Grant BF. The alcohol use disorder and associated disabilities interview schedule (AUDADIS): reliability of alcohol and drug modules in a clinical sample. Drug Alcohol Depend 1997; 44: 133-41.

43 Chatterji S, Saunders JB, Vrasti R, Grant BF, Hasin D, Mager D. Reliability of the alcohol and drug modules of the Alcohol Use Disorder and Associated Disabilities Interview Schedule-Alcohol/Drug-Revised (AUDADIS-ADR): an international comparison. Drug Alcohol Depend; 47: 171-85.

44 Hasin D, Paykin A. Alcohol dependence and abuse diagnoses: concurrent validity in a nationally representative sample. Alcohol Clin Exp Res 1999; 23 $144-50$.

45 Hasin DS, Muthuen B, Wisnicki KS, Grant B. Validity of the bi-axial dependence concept: a test in the US general population. Addiction 1994; 89: 573-9.

46 Hasin DS, Van Rossem R, McCloud S, Endicott J. Differentiating DSM-IV alcohol dependence and abuse by course: community heavy drinkers. J Subst Abuse 1997; 9: 127-35.

47 Cottler LB, Grant BF, Blaine J, Mavreas V, Pull C, Hasin D, et al. Concordance of DSM-IV alcohol and drug use disorder criteria and diagnoses as measured by AUDADIS-ADR, CIDI and SCAN. Drug Alcohol Depend 1997; 47: 195-205.

48 Pull CB, Saunders JB, Mavreas V, Cottler LB, Grant BF, Hasin DS, et al. Concordance between ICD-10 alcohol and drug use disorder criteria and diagnoses as measured by the AUDADIS-ADR, CIDI and SCAN: results of a cross-national study. Drug Alcohol Depend 1997; 47: 207-16.

49 Ustün B, Compton W, Mager D, Babor T, Baiyewu O, Chatterji S, et al. WHO Study on the reliability and validity of the alcohol and drug use disorder instruments: overview of methods and results. Drug Alcohol Depend 1997; 47: 161-9.

50 Vrasti R, Grant BF, Chatterji S, Ustün BT, Mager D, Olteanu I, et al. Reliability of the Romanian version of the alcohol module of the WHO Alcohol Use Disorder and Associated Disabilities: Interview Schedule Alcohol/Drug-Revised. Eur Addict Res 1998; 4: 144-9.

51 Eaton NR, Keyes KM, Krueger RF, Balsis S, Skodol AE, Markon KE, et al. An invariant dimensional liability model of gender differences in mental disorder prevalence: evidence from a national sample. J Abnorm Psycho 2011; Aug 15 (Epub ahead of print).

$52 \mathrm{Hu}$ L, Bentler PM. Cutoff criteria for fit indexes in covariance structure analysis: conventional criteria versus new alternatives. Struct Equ Modeling 1999; 6: 1-55

53 Asparouhov T, Muthen B. Robust Chi Square Difference Testing with Mean and Variance Adjusted Test Statistics. Mplus Web Notes: No. 10. Muthen \& Muthen, 2006 (http://www.statmodel.com/download/webnotes/ webnote10.pdf).

54 Muthen B, Muthen L. Mplus User's Guide (5th Edition). Muthen \& Muthen 2010 (http://www.statmodel.com/ugexcerpts.shtml).

55 McLaughlin KA, Green JG, Gruber MJ, Sampson NA, Zaslavsky AM, Kessler RC. Childhood adversities and adult psychiatric disorders in the national comorbidity survey replication II: associations with persistence of DSM-IV disorders. Arch Gen Psychiatry 2010; 67: 124-32.

56 Dong M, Anda RF, Felitti VJ, Dube SR, Williamson DF, Thompson TJ, et al. The interrelatedness of multiple forms of childhood abuse, neglect, and household dysfunction. Child Abuse Negl 2004; 28: 771-84.

57 Green JG, McLaughlin KA, Berglund PA, Gruber MJ, Sampson NA, Zaslavsky AM, et al. Childhood adversities and adult psychiatric disorders in the national comorbidity survey replication I: associations with first onset of DSM-IV disorders. Arch Gen Psychiatry 2010; 67: 113-23. 
58 Finkelhor D, Ormrod RK, Turner HA. Poly-victimization: a neglected component in child victimization. Child Abuse Negl 2007; 31: 7-26.

59 Molnar BE, Buka SL, Kessler RC. Child sexual abuse and subsequent psychopathology: results from the National Comorbidity Survey. Am J Public Health 2001; 91: 753-60.

60 Ogata SN, Silk KR, Goodrich S, Lohr NE, Westen D, Hill EM. Childhood sexual and physical abuse in adult patients with borderline personality disorder Am J Psychiatry 1990; 147: 1008-13.

61 Rowan $A B$, Foy DW. Post-traumatic stress disorder in child sexual abuse survivors: a literature review. J Trauma Stress 1993; 6: 3-20.

62 Schulz-Heik RJ, Rhee SH, Silvern LE, Haberstick BC, Hopfer C, Lessem JM et al. The association between conduct problems and maltreatment: testing genetic and environmental mediation. Behav Genet 2010; 40: 338-48.

63 Linsky AS, Straus MA, Colby Jr JP. Stressful events, stressful conditions and alcohol problems in the United States: a partial test of Bales's theory. J Stud Alcohol 1985; 46: 72-80.

64 Dube SR, Anda RF, Felitti VJ, Edwards VJ, Williamson DF. Exposure to abuse neglect, and household dysfunction among adults who witnessed intimate partner violence as children: implications for health and social services. Violence Vict 2002; 17: 3-17.

65 Turner HA, Finkelhor D, Ormrod R. The effect of lifetime victimization on the mental health of children and adolescents. Soc Sci Med 2006; 62: 13-27.

66 Dinwiddie SH, Bucholz KK. Psychiatric diagnoses of self-reported child abusers. Child Abuse Negl 1993; 17: 465-76.

67 Conron KJ, Beardslee W, Koenen KC, Buka SL, Gortmaker SL. A longitudinal study of maternal depression and child maltreatment in a national sample of families investigated by child protective services. Arch Pediatr Adolesc Med 2009; 163: 922-30.

68 Besinger B, Garland AF, Litrownik AJ, Landsverk JA. Caregiver substance abuse among maltreated children placed in out-of-home care. Child Welfare 1999; 78: 221-39.
69 Chaffin M, Kelleher $\mathrm{K}$, Hollenberg J. Onset of physical abuse and neglect: psychiatric, substance abuse, and social risk factors from prospective community data. Child Abuse Negl 1996; 20: 191-203.

70 Kelleher K, Chaffin M, Hollenberg J, Fischer E. Alcohol and drug disorders among physically abusive and neglectful parents in a community-based sample. Am J Public Health 1994; 84: 1586-90.

71 Hardt J, Rutter M. Validity of adult retrospective reports of adverse childhood experiences: review of the evidence. J Child Psychol Psychiatry 2004; 45: 260-73.

72 Williams LM. Recall of childhood trauma: a prospective study of women's memories of child sexual abuse. J Consult Clin Psychol 1994; 62: 1167-76.

73 Widom CS. Accuracy of adult recollection of childhood victimization: Part 2. Childhood sexual abuse. Psychol Assess 1997; 9: 34-46.

74 Widom CS. Accuracy of adult recollection of chilhood victimization: Part I. Childhood physical abuse. Psychol Assess 1996; 8: 412-21.

75 Fergusson DM, Horwood L, Woodward L. The stability of child abuse reports: a longitudinal study of the reporting behaviour of young adults. Psychol Med 2000; 30: 529-44.

76 Scott KM, Smith DR, Ellis PM. Prospectively ascertained childhood maltreatment and its associations with DSM-IV mental disorders in young adults. Arch Gen Psychiatry 2010; 67: 712-9.

77 Kessler RC, Davis CG, Kendler KS. Childhood adversity and adult psychiatric disorder in the US National Comorbidity Survey. Psychol Med 1997; 27: 1101-19.

78 Fisher $\mathrm{HL}$, Jones PB, Fearon $\mathrm{P}$, Craig TK, Dazzan P, Morgan $\mathrm{K}$, et al. The varying impact of type, timing and frequency of exposure to childhood adversity on its association with adult psychotic disorder. Psychol Med 2010; 40: 1967-78.

79 Barker-Collo S, Read J. Models of response to childhood sexual abuse: their implications for treatment. Trauma Violence Abuse 2003; 4: 95-111.

80 Read J, Hammersley P, Rudegeair T. Why, when and how to ask about childhood abuse. Adv Psychiatric Treat 2007; 13: 101-10. 